\title{
Improved symptom relief and duodenal ulcer healing with lansoprazole, a new proton pump inhibitor, compared with ranitidine
}

\author{
C J Hawkey, R G Long, K D Bardhan, K G Wormsley, K M Cochran, J Christian, \\ I K Moules
}

\begin{abstract}
The purpose of this study was to compare duodenal ulcer healing, symptom relief, and safety of lansoprazole (a new proton pump inhibitor) given at doses of $30 \mathrm{mg}$ and $60 \mathrm{mg}$, in the morning with ranitidine $300 \mathrm{mg}$ at bedtime. Two hundred and eighty nine patients were enrolled over a 20 month period in a double blind randomised parallel group comparative study set in outpatient endoscopy units of six United Kingdom medical centres. Patients were randomised to receive lansoprazole $30 \mathrm{mg}$ in the morning ( $\mathrm{n}=95), 60 \mathrm{mg}$ in the morning $(n=96)$, or ranitidine $300 \mathrm{mg}$ at bedtime $(n=98)$ for four weeks. Efficacy was assessed by gastroscopy at study entry and after two and four weeks of treatment. Symptom relief was monitored by patient diaries and physician review at two and four weeks. Both doses of lansoprazole resulted in significantly greater ulcer healing than ranitidine after two and four weeks. Respective healing rates on lansoprazole $30 \mathrm{mg}, 60 \mathrm{mg}$, and ranitidine $300 \mathrm{mg}$ were $78 \%, 80 \%$, and $60 \%$ after two weeks and $93 \%, 97 \%$, and $81 \%$ after four weeks. Patients on lansoprazole $30 \mathrm{mg}$ $(p=0.002)$ and lansoprazole $60 \mathrm{mg}(p=0.026)$ also recorded greater relief of night time pain in the diary cards during the first seven days of treatment than those on ranitidine. Patients on lansoprazole $60 \mathrm{mg}$ reported significantly better pain relief at their two week visit compared with those receiving ranitidine $(p=0 \cdot 007)$. There were no differences between treatment groups in the occurrence or pattern of adverse drug reactions during the trial. It is concluded that for patients with duodenal ulcer, lansoprazole $30 \mathrm{mg}$ or $60 \mathrm{mg}$ is associated with faster ulcer healing and better symptom relief than ranitidine $300 \mathrm{mg}$ at bedtime. There were no significant differences between lansoprazole $30 \mathrm{mg}$ and $60 \mathrm{mg}$. These data indicate that lansoprazole should be used at a once daily dose of $\mathbf{3 0} \mathbf{~ m g}$ for the treatment of duodenal ulcer.

(Gut 1993; 34: 1458-1462)
\end{abstract}

The efficacy of inhibitors of gastric acid secretion in healing duodenal ulcers has been repeatedly confirmed during the past 18 years. More recent- ly the discovery of substituted benzimidazoles, which inhibit the $\left(\mathrm{H}^{+}, \mathrm{K}^{+}\right)$ATPase (proton pump) of the parietal cell ${ }^{1}$ has led to the development of compounds that can profoundly inhibit gastric acid production. Lansoprazole is a novel member of this new generation of acid inhibiting drugs, the proton pump inhibitors. It selectively inhibits the proton pump in vitro ${ }^{23}$ and in vivo. Human clinical pharmacology studies have shown profound and prolonged suppression of 24 hour intragastric acidity with single 15 or $30 \mathrm{mg}$ doses of lansoprazole, which increased with repeated doses. ${ }^{56}$ In addition a single $60 \mathrm{mg}$ dose produced almost total inhibition of 24 hour gastric acidity as well as inhibiting pentagastrin stimulated acid secretion by $92 \% .^{6}$ Early clinical studies with lansoprazole showed a dose related increase in duodenal ulcer healing rates at daily doses of $7.5 \mathrm{mg}, 15 \mathrm{mg}$ and $30 \mathrm{mg} .^{7} \mathrm{We}$, therefore, compared lansoprazole at single daily doses of $30 \mathrm{mg}$ and $60 \mathrm{mg}$ in the morning with ranitidine $300 \mathrm{mg}$ at bedtime for four weeks in the treatment of patients with duodenal ulcer, to investigate whether these doses of lansoprazole were superior to ranitidine and determine which was optimal. Efficacy was assessed by endoscopic evidence of healing and by symptomatic relief. Safety was monitored in terms of clinical adverse events as well as biochemical and haematological screening.

\section{Methods}

\section{STUDY DESIGN}

The study was a double blind, randomised, parallel group comparison of lansoprazole $30 \mathrm{mg}$, lansoprazole $60 \mathrm{mg}$ both in the morning and ranitidine $300 \mathrm{mg}$ at bedtime conducted at six hospitals in Nottingham, Rotherham, Glasgow, and Dundee, United Kingdom.

\section{PATIENT SELECTION}

Patients between the ages of 18 and 75 (inclusive), with duodenal ulcer(s) proved by endoscopy greater than $3 \mathrm{~mm}$ but not more than $2.5 \mathrm{~cm}$ in diameter were eligible if they had not received therapeutic doses of ulcer treatment in the previous six days or bismuth within the previous three months. Standard exclusion 
criteria were used, the principal ones being concomitant reflux oesophagitis, oesophageal stricture, Barrett's oesophagus, gastric ulceration, upper gastrointestinal bleeding, gastrointestinal malignancy, previous gastric surgery, inflammatory bowel disease, or any serious cardiac, renal or hepatic disorders. Women of child bearing potential could be enroled provided they were practising effective contraception. Patients taking steroids or anti-coagulants were excluded.

\section{TREATMENT}

Patients were stratified for smoking habits before randomisation (in blocks of three at each centre) to receive lansoprazole $30 \mathrm{mg}$ or $60 \mathrm{mg}$ in the morning or ranitidine $300 \mathrm{mg}$ at bedtime. Drugs and placebo were provided as white, hard gelatin capsules in blister packs to maintain blinding. Patients took two capsules in the morning half an hour before food and two capsules at night before retiring. Patients received treatment for 28 ( + or minus three days) regardless of healing state (see below). Maalox tablets were provided for additional symptom relief as required.

\section{EVALUATIONS}

Patients were entered into the study within seven days of an endoscopy showing active duodenal ulceration. Duodenal ulcer was defined as a break in the mucosa distal to the opening of the pylorus with excavation and slough at the base. Healing was monitored by repeat endoscopy performed after 14 ( + or minus three days) of treatment, and (in those unhealed at 14 days) after 28 ( + or minus three days).

The occurrence of pain, nausea, and vomiting (occasional, daily, continual) over the previous week were assessed by the investigator at each visit. In addition, patients recorded day and night time pain (none, mild, moderate, severe) and antacid consumption on a daily diary card. Compliance was monitored by capsule count at each visit. Safety evaluation was based upon adverse event monitoring as well as physical examination, urinalysis, blood count, urea and electrolytes, liver function tests, uric acid, calcium and phosphate estimations.

\section{STATISTICAL METHODS}

The primary end point was cumulative ulcer healing in evaluable patients (all those having an endoscopy at a particular visit). This can be regarded as a pragmatic approach. ${ }^{8}$ In addition a secondary 'per protocol' analysis was performed, in those patients who met the eligibility criteria (patient selection) and evaluability criteria (repeat endoscopy within three days of specified time having taken $75 \%$ of treatment) as specified in the protocol. Healing rates at weeks 2 and 4 were compared across treatment groups using a $3 \times 2 \chi^{2}$. If this was at or near the $5 \%$ significance value, pairwise comparisons between groups were made using the $\chi^{2}$ test (with continuity correction) or Fisher's exact test, and 95\% confidence intervals were constructed for each pairwise difference. ${ }^{9}$ Multivariate logistic
TABLE I Demography of patients studied

\begin{tabular}{llll}
\hline & $\begin{array}{l}\text { Lansoprazole } \\
30 \mathrm{mg}\end{array}$ & $\begin{array}{l}\text { Lansoprazole } \\
60 \mathrm{mg}\end{array}$ & $\begin{array}{l}\text { Ranitidine } \\
300 \mathrm{mg}\end{array}$ \\
\hline No of patients & 95 & 96 & 98 \\
M/F & $71 / 24$ & $65 / 31$ & $68 / 30$ \\
Mean age (SD) & $43(14)$ & $46(16)$ & $48(13)$ \\
Smokers (\%) & 57 & 67 & 63 \\
Drinkers (\%) & 73 & 69 & 60 \\
Receiving NSAIDs (\%) & 2 & 5 & 7 \\
New patient (\%) & 42 & 59 & 53 \\
Relapsed (\%) & 57 & 40 & 47 \\
Refactory (\%) & 1 & 1 & 0 \\
History (\%) & & & \\
$\quad<1$ year & 15 & 25 & 22 \\
$\quad$ 1-5 years & 44 & 32 & 38 \\
$>5$ years & 41 & 41 & 40 \\
\hline
\end{tabular}

NSAIDs $=$ non-steroidal anti-inflammatory drugs.

regression analysis ${ }^{10}$ was used to assess the influence of prognostic factors and to justify the pooling of response data across trial centres (centre/treatment interaction). The KruskalWallis test was used to compare the frequency of pain and antacid use, and adverse events. Analysis of variance was used to assess changes in laboratory values. All calculations were performed using the SAS package. ${ }^{112}$

Sample size was calculated assuming a healing rate of $65 \%$ with ranitidine at week 2 . With 95 patients in each treatment group, a $20 \%$ improvement with either lansoprazole group could be detected with a power of $80 \%$ at a two sided significance value of $5 \% .{ }^{13}$

\section{Results}

Two hundred and eighty nine patients were enroled into the study over a period of 20 months. One hundred and eighty were smokers and 109 were non or former smokers. Table I shows the distribution of patient characteristics across the three treatment groups. Age, sex, smoking, and alcohol use seem to be relatively well balanced across the treatment groups. Any effect these factors may have had on healing rates were examined using logistic regression analysis.

\section{ULCER HEALING}

The primary analysis showed a statistically significant difference across treatment groups both at week $2(p=0.005)$ and week $4(p=0 \cdot 001)$. Pairwise comparisons showed that the superiority of healing rates with both doses

TABLE II Healing rates in evaluable patients

\begin{tabular}{|c|c|c|c|}
\hline & $\begin{array}{l}\text { Lansoprazole } \\
30 \mathrm{mg}\end{array}$ & $\begin{array}{l}\text { Lansoprazole } \\
60 \mathrm{mg}\end{array}$ & $\begin{array}{l}\text { Ranitidine } \\
300 \mathrm{mg}\end{array}$ \\
\hline No of patients & 95 & 96 & 98 \\
\hline $\begin{array}{l}\text { Week 2: No of patients } \\
\text { healed }(\%)\end{array}$ & $\begin{array}{l}65 / 83 \\
(78 \cdot 3)\end{array}$ & $\begin{array}{l}67 / 84 \\
(79 \cdot 8)\end{array}$ & $\begin{array}{l}52 / 87 \\
(59 \cdot 8)\end{array}$ \\
\hline $\begin{array}{l}\text { \% Difference }(95 \% \mathrm{CI}) \\
\text { compared with } \\
\text { ranitidine }\end{array}$ & $\begin{array}{l}18 \cdot 5 \\
(4 \cdot 9,32 \cdot 1)\end{array}$ & $\begin{array}{l}20 \cdot 0 \\
(6 \cdot 6,33 \cdot 4)\end{array}$ & - \\
\hline $\begin{array}{l}\text { Week 4: No of patients } \\
\text { healed }(\%)\end{array}$ & $\begin{array}{l}81 / 87 \\
(93 \cdot 1)\end{array}$ & $\begin{array}{l}87 / 90 \\
(96 \cdot 7)\end{array}$ & $\begin{array}{l}75 / 92 \\
(81 \cdot 5)\end{array}$ \\
\hline $\begin{array}{l}\text { \% Difference }(95 \% \mathrm{CI}) \\
\text { compared with } \\
\text { ranitidine }\end{array}$ & $\begin{array}{l}11 \cdot 6 \\
(2 \cdot 0,21 \cdot 2)\end{array}$ & $\begin{array}{l}15 \cdot 2 \\
(6 \cdot 5,24 \cdot 0)\end{array}$ & - \\
\hline
\end{tabular}

«Difference lansoprazole $30 \mathrm{mg} v$ lansoprazole $60 \mathrm{mg}(95 \% \mathrm{CI})$ : week $2:-1 \cdot 5 \%(-13 \cdot 8,10 \cdot 8)$; week $4:-3 \cdot 6 \%(-10 \cdot 1,2 \cdot 9)$. 
TABLE III Healing rates in per protocol analysis

\begin{tabular}{clll}
\hline & $\begin{array}{l}\text { Lansoprazole } \\
30 \mathrm{mg}\end{array}$ & $\begin{array}{l}\text { Lansoprazole } \\
60 \mathrm{mg}\end{array}$ & $\begin{array}{l}\text { Ranitidine } \\
300 \mathrm{mg}\end{array}$ \\
\hline $\begin{array}{l}\text { Week 2: No of patients } \\
\text { healed (\%) }\end{array}$ & $\begin{array}{l}43 / 55 \\
(78 \cdot 2)\end{array}$ & $\begin{array}{l}44 / 55 \\
(80 \cdot 0)\end{array}$ & $\begin{array}{l}29 / 53 \\
(54 \cdot 7)\end{array}$ \\
$\begin{array}{c}\text { \% Difference (95\% CI) } \\
\text { compared with }\end{array}$ & $23 \cdot 5$ & $25 \cdot 3$ & - \\
$\begin{array}{c}\text { ranitidine } \\
\begin{array}{l}\text { Week 4: No of patients } \\
\text { healed (\%) }\end{array}\end{array}$ & $(6 \cdot 2,40 \cdot 8)$ & $(8 \cdot 2,42 \cdot 4)$ & \\
$\begin{array}{c}\text { \% Difference } \\
\text { compared with }\end{array}$ & $(92 \cdot 9)$ & $58 / 59$ & $43 / 53$ \\
ranitidine & $(-0 \cdot 7,24 \cdot 3)$ & $(98 \cdot 3)$ & $(81 \cdot 1)$ \\
\hline
\end{tabular}

of lansoprazole compared with ranitidine were statistically significant at both week 2 and week 4 (Table II). There was no difference between the response rates in the two lansoprazole groups at either time point. The per protocol analysis supported this result (Table III). The difference between lansoprazole $30 \mathrm{mg}$ or $60 \mathrm{mg}$ and ranitidine remained statistically significant at week 2 in this group. There was no difference between the two lansoprazole groups (difference $-1 \cdot 8 \%, 95 \%$ confidence intervals $-17 \cdot 0,13 \cdot 4)$.

Smoking and drinking habits, sex, number of lesions, and treatment were included as possible factors affecting healing at the two week assessment in the multivariate analysis (the analysis was not performed at four weeks as the proportion of patients healed was high, $80-90 \%)$. The
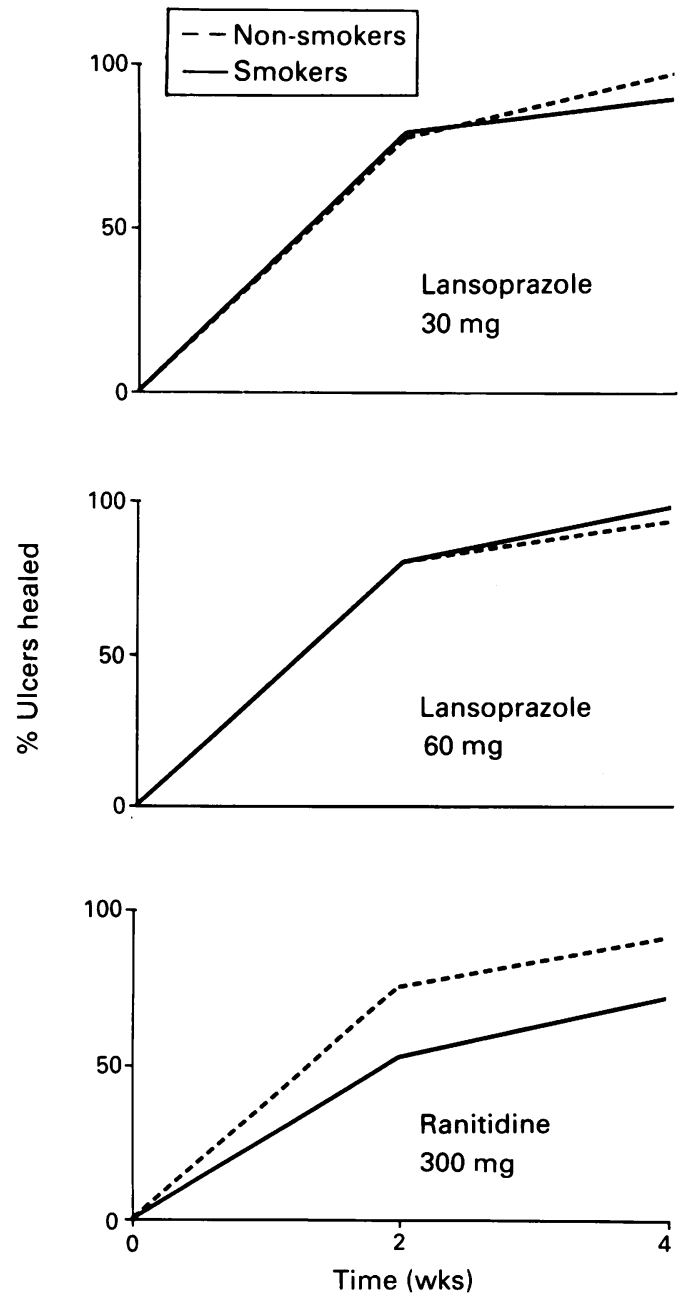

Figure 1: Effect of smoking on ulcer healing shown by drug treatment.

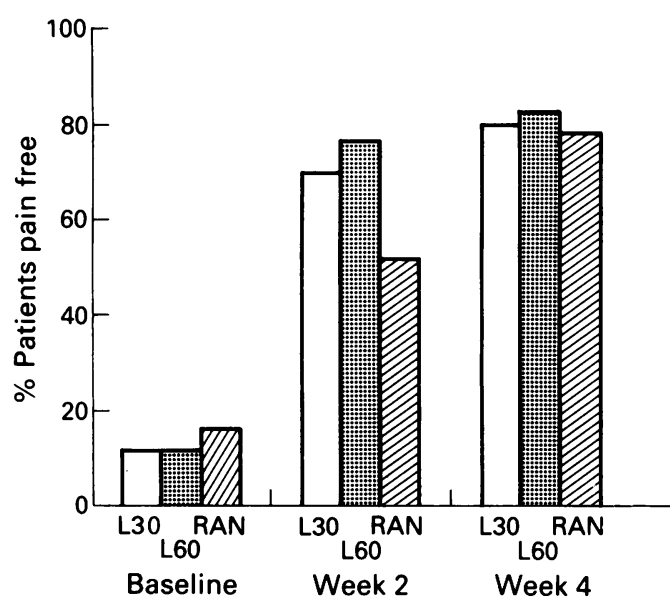

Figure 2: Effect of drug treatments on the number of patients reporting no symptoms in the seven days before clinic visit. L 30= lansoprazole $30 \mathrm{mg}, \mathrm{L} 60=$ lansoprazole $60 \mathrm{mg}$, $R A N=$ ranitidine.

number of patients receiving non-steroidal antiinflammatory drugs in each group was too small to include in the model. Although the study was stratified for smoking habits as a possible prognostic factor this was not confirmed in this study. This was probably due to similar healing rates for smokers and non former smokers receiving either dose of lansoprazole (Fig 1).

The analysis showed a difference in healing rates across centres in the per protocol analysis but not the evaluable patient group. All treatments were equally affected, however, (treatment/centre interactions not significant, $\mathrm{p}=0.51$ ) so that the odds ratios for lansoprazole $v$ ranitidine adjusted for centre effect was consistent with the unadjusted odds ratio (lansoprazole

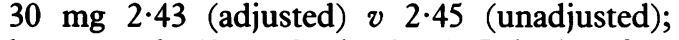
lansoprazole $60 \mathrm{mg} 2.65 v 2.61$ ). It is therefore justified to pool data across centres.

\section{PAIN RELIEF}

After two weeks of treatment there was a statistically significant difference between the treatment groups $(p=0.027)$ in the reduction of the percentage of patients reporting themselves to have experienced pain in the previous week. Pairwise comparisons showed this to be due to a significantly greater improvement in patients receiving lansoprazole $60 \mathrm{mg}$ compared with those receiving ranitidine $(p=0.007)$. There was no difference between the two lansoprazole groups $(p=0 \cdot 19)$. There was no difference across the treatment groups after four weeks of treatment $(p=0 \cdot 24)$. Figure 2 shows the proportion of patients pain free at each time point.

\section{PATIENT DIARY ASSESSMENTS}

Patient diary records also showed improved symptom relief. Lansoprazole was associated with a significantly greater reduction of night time pain after seven days of treatment compared with ranitidine (Fig 3, p =0.002 for lansoprazole $30 \mathrm{mg} v$ ranitidine, $\mathrm{p}=0.026$ for lansoprazole $60 \mathrm{mg} v$ ranitidine). There was no difference between the two lansoprazole groups $(p=0 \cdot 12)$. Differences in the extent of improvement in 


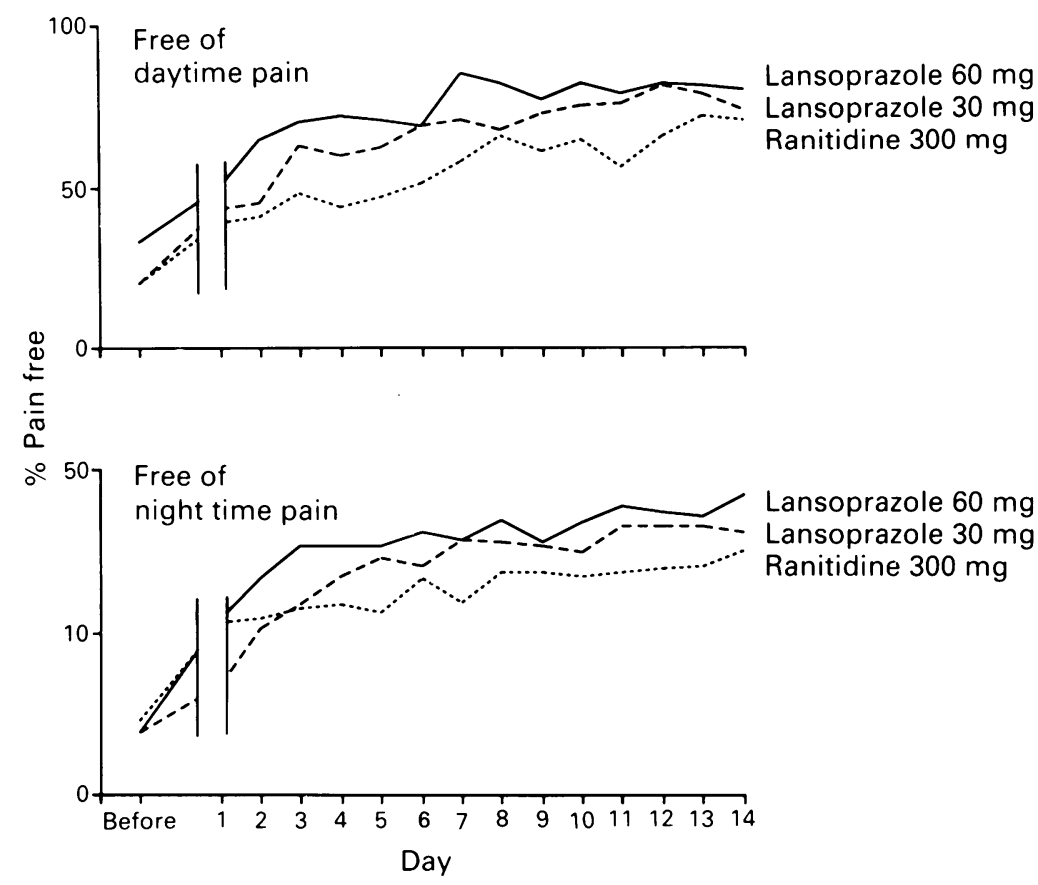

Figure 3: Effect of drug treatments on symptoms recorded in the diary card.

daytime pain did not reach statistical significance $(\mathrm{p}=0 \cdot 37)$.

\section{ANTACID USE}

The degree of pain relief was reflected in the consumption of antacids. There was a statistically significant $(p=0.018)$ difference between the three treatment groups in the proportion of days on which antacids were taken. Patients receiving lansoprazole $30 \mathrm{mg}$ took antacids on $12 \cdot 7 \%$ (median) of days. Those on lansoprazole $60 \mathrm{mg}$ took them on $15 \cdot 7 \%$ of days, and those on ranitidine $25 \cdot 5 \%$ of days. Pairwise comparisons showed the difference between those receiving lansoprazole $30 \mathrm{mg}$ and those receiving ranitidine $300 \mathrm{mg}$ was significant $(p=0.005)$, while that between those receiving lansoprazole $60 \mathrm{mg}$ and those receiving ranitidine approached statistical significance $(\mathrm{p}=0 \cdot 06)$. There was no difference between the two lansoprazole groups $(p=0.973)$.

\section{SAFETY}

A total of 91 clinical adverse events was reported (32 on lansoprazole $30 \mathrm{mg}, 31$ on lansoprazole

TABLE IV Most frequently reported adverse events

\begin{tabular}{|c|c|c|c|}
\hline & $\begin{array}{c}\text { Lansoprazole } \\
30 \mathrm{mg}\end{array}$ & $\begin{array}{l}\text { Lansoprazole } \\
\quad 60 \mathrm{mg}\end{array}$ & $\begin{array}{l}\text { Ranitidine } \\
300 \mathrm{mg}\end{array}$ \\
\hline $\begin{array}{l}\text { Pain } \\
\text { Dizziness } \\
\text { Headache } \\
\text { Constipation } \\
\text { Diarrhoea } \\
\text { Nausea } \\
\text { Depression } \\
\text { Rhinitis } \\
\text { Laboratory } \\
\text { changes }\end{array}$ & $\begin{array}{c}1 \\
1 \\
2 \\
2 \\
2 \\
2 \\
0 \\
3 \\
\uparrow \gamma \text {-glutanyl- } \\
\text { transferase (1) } \\
\uparrow \text { mean cell } \\
\text { volume (1) }\end{array}$ & $\begin{array}{c}3 \\
1 \\
2 \\
2 \\
1 \\
0 \\
3 \\
2 \\
\uparrow \gamma \text {-glutanyl- } \\
\text { tranferase (1) } \\
\uparrow \text { uric acid (1) }\end{array}$ & $\begin{array}{c}0 \\
2 \\
3 \\
0 \\
4 \\
3 \\
1 \\
1 \\
\downarrow \text { leucocytes (1) } \\
\downarrow \text { platelets (1) } \\
\downarrow \text { alkaline } \\
\text { phosphatase (1) } \\
\downarrow \downarrow \text { alanine } \\
\text { transaminase (1) } \\
\text { abnormal liver } \\
\text { function tests (1) }\end{array}$ \\
\hline
\end{tabular}

$60 \mathrm{mg}, 28$ on ranitidine). Thirty five were regarded as possibly, probably or definitely drug related. Ten of these occurred on lansoprazole $30 \mathrm{mg}, 13$ on lansoprazole $60 \mathrm{mg}, 12$ on ranitidine. Table IV shows the most frequently reported events (regardless of drug relation that is, all events). Statistical testing was performed taking into account severity (mild, moderate, severe) as well as incidence of each event. There was no statistically significant difference between the three treatment groups in the incidence/severity of any adverse event. Likewise no differences were apparent across treatment groups when only drug related events were considered (no statistical comparison was made as the numbers were too small).

\section{LABORATORY CHANGES}

Changes in haematology and serum biochemistry values after four weeks of treatment were small and not of any clinical relevance. Statistically significant differences between the treatment groups were noted for chloride (increase in patients receiving ranitidine after four but not two weeks) and sodium (increase in patients receiving lansoprazole after two but not four weeks) but the changes were small and of no clinical relevance and are likely to be a chance finding because of the number of statistical comparisons made. ${ }^{36}$

There were 15 individual instances of abnormal laboratory values regarded as clinically significant by the investigator, of which nine were regarded as possibly (8) or probably (1) drug related ( 2 on lansoprazole $30 \mathrm{mg}, 2$ on lansoprazole $60 \mathrm{mg}, 5$ on ranitidine). Table IV gives details of these instances.

\section{Discussion}

Our data show that both doses of lansoprazole are superior to ranitidine in healing duodenal ulcers both in terms of the rate of healing and in the proportion of patients healed after a standard four week course of treatment (93-97\% v 81\%). Roughly as many patients are healed after two weeks of lansoprazole $(78-80 \%)$ as after four weeks of ranitidine $(81 \%)$, emphasising that ulcer healing is achievable with shorter courses of treatment than with the $\mathrm{H}_{2}$ receptor antagonists. It is also interesting to note that the healing rates were similar in smokers and nonsmokers in patients receiving lansoprazole. This could be a result of lansoprazole achieving more effective acid inhibition.

Acid suppression may also account for the improved symptom relief with lansoprazole that accompanied the accelerated ulcer healing. This symptomatic improvement was achieved with a concomitant decrease in antacid consumption in patients receiving lansoprazole as a further indicator of the effectiveness of symptom relief. Diary card symptoms were analysed in terms of changes in the number of days or nights in which pain was experienced. Lansoprazole was superior to ranitidine for night time pain during the first seven days but thereafter the rate of change levelled off with most patients being asymptomatic, particularly on lansoprazole. 
Likewise, a higher number of patients taking lansoprazole were free of daytime pain but a higher proportion of those on lansoprazole $60 \mathrm{mg}$ had been symptom free before treatment and differences between drugs in the changes in diary card symptoms did not achieve statistical significance.

Assessment of safety and adverse drug reactions show that lansoprazole combines high efficacy with apparent absence of any serious side effects. The incidence and severity of adverse events in patients receiving lansoprazole at either dose did not differ from those of patients receiving ranitidine. There were no unusual adverse events associated with the use of lansoprazole. Detailed analysis of laboratory parameters showed no clinically significant changes in those measured.

Healing rates in our study are similar to those previously reported in dose ranging placebo controlled comparisons. ${ }^{714}$ These studies have suggested dose dependence up to $30 \mathrm{mg}$ and that this dose seems to be superior at two weeks to ranitidine $300 \mathrm{mg}^{7}$ and famotidine $40 \mathrm{mg} .{ }^{13} \mathrm{In}$ our studies there were no significant differences between the two doses of lansoprazole in either efficacy or safety. Response rates and symptom relief seemed to be slightly higher with the $60 \mathrm{mg}$ than the $30 \mathrm{mg}$ dose, but the difference was minimal and never statistically significant. An effective dose, therefore, seems to be $30 \mathrm{mg}$ per day for rapid symptom relief and ulcer healing, without significant adverse events.
We thank Tim McAuliffe for statistical analysis, Mrs Elaine Chick as Data Co-ordinator and Mrs Carole Weaver for typing this as Data Co-or

Presented as an oral paper to the American Gastroenterology Association Digestive Diseases Week, May 1991.

1 Fellenius E, Berglindh T, Sachs G, et al. Substituted benzimidazoles inhibit gastric acid secretion by blocking $\left(\mathrm{H}^{+}, \mathrm{K}^{+}\right)$ATPase. Nature 1981; 290: 159-61.

2 Nagaya $\mathrm{H}$, Satoh $\mathrm{H}$, Kubo K, Maki Y. Possible mechanism for

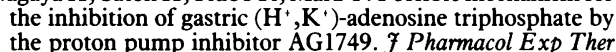
the proton pump in
1989; 248: 799-805.

3 Nagaya $H$, Satoh H, Maki Y. Possible mechanism for the inhibition of acid formation by the proton pump inhibito AG1749 in isolated canine parietal cells. $\mathcal{F}$ Pharmacol Exp Ther 1990; 252: 1289-95.

4 Satoh $\mathrm{H}$, Inatomi N, Nagaya $\mathrm{H}$, et al. Anti-secretory and antiulcer activities of a proton pump inhibitor AG1749 in dogs ulcer activities of a proton pump inhibitor AG
and rats. $\mathcal{F}$ Pharm Exp Ther 1989; 248: 806-15.

5 Muller P, Dammann HG, Leucht U, Simon B. Human gastric acid secretion following repeated doses of AG-1749. Alimen Pharmacol Ther 1989; 3: 193-8.

6 Baradell LB, Faulda D, McTavish D. Lansoprazole. A review of its pharmacodynamic and pharmacokinetic properties and its therapeutic efficacy in acid-related disorders. Drugs 1992; 44: 225-50.

7 Longdong W, Barth H, Dammann HG, et al. Dose-related healing of duodenal ulcer with the proton pump inhibito lansoprazole. Aliment Pharmacol Ther 1991; 5: 245-54.

8 Schwartz D, Lellouch J. Explanatory and pragmatic attitudes in clinical trials. F Cronic Dis 1967; 20: 637-8.

9 Fleiss JL. Statistical methods for rates and proportions. 2nd ed. New York: Wiley, 1981.

10 Cox DR. The analysis of binary data. London: Methuen, 1970.

11 SAS User's Guide: statistics. Version 5. Cary, NC: SAS Institute Inc, 1985.

12 SAS SUGI Supplemental Library User's Guide. Cary, NC: SAS Institute Inc, 1983.

13 Machin D, Campbell MJ. Statistical tables for the design of clinical trials. Blackwell Scientific, Oxford, 1987.

14 Hotz J, Kleiner R, Grymbowski T, Hennig U, Schwartz JA. Lansoprazole versus famotidine: efficacy and tolerance in the acute management of duodenal ulceration. Aliment Pharmacol Ther 1992; 6: 87-95. 